\title{
Tiyatro Oyuncularının Duygusal Zeka Düzeyleri ve İlişkili Faktörler
}

DOI: $10.26466 /$ opus.639984

\author{
$*$ \\ Nükhet Kırağ - Manolya Ercan** \\ * Dr. Öğr. Üyesi, Adnan Menderes Üniversitesi, Hemşirelik Fakültesi, Efeler/ Aydın / Türkiye \\ E-Posta: nukhetkirag@gmail.com ORCID: 0000-0001-8223-2996 \\ ** Hemşire, Aydın Kadın Doğum ve Çocuk Hastalıkları Hastanesi, Efeler / Aydın/ Türkiye \\ E-Posta: manolyaaa.yildiz@gmail.com ORCID: 0000-0002-1327-1657
}

$\ddot{O} z$

Duygusal zeka, duyguların daha mantıklı kullanılmasına etki ederek olumlu yaşam ve profesyonel ilişkilerin verimli yönetilmesine katkıda bulunur. Tiyatro oyuncularının duygusal zeka düzeylerinin incelenmesi amaçlanmıştır. Bu araştırma Eylül-Aralık 2018 tarihleri arasında Aydın il merkezinde yaşayan ve tiyatro oyunculuğu yapan 143 kişi ile yürütülmüştür. Araştırma verilerinin toplanmasında araştırmacılar tarafindan hazırlanan sosyodemografik özellikler formu ve Bar on Duygusal Zekâ Ölçeği kullanılmıştır. Verilerin değerlendirilmesinde SPSS 16 programı ile yüzde, kikare, bağımsız gruplarda $t$ testi ve Anova testleri kullanılmıştır. Araştırmada yer alan bireylerin yaş ortalaması 28.5 $\pm 9.48, \% 54.5^{\prime} i$ kadın, \%67.1'i bekar, \%11.2'sinin ruhsal bir hastalı tanısı bulunmakta, \%64.3'ü kendisini girişken olarak tanımlıyor, \%76.2'si bir problem karşısında sebebini düşünüp düzeltmeye çalıştı̆̆ ifade ediyor, \%76.2'si tiyatro oyunculuğunu tatmin edici bir meslek olduğunu ifade ediyor, \%46.9'unun gelirini giderinden az buluyor. Bar on Duygusal Zeka Düzeyi Ölçeği puan ortalamastnın $291.35 \pm 18.40$ olduğu saptanmıştır. Ölçek puan ortalaması ile gelir düzeyi ve tiyatro oyunculuğu yapma yılı arasında istatistiksel olarak anlamlı bir ilişki bulunmuştur $(p<0.05)$. Tiyatro oyunculuğu yapan bireylerin duygusal zeka düzeylerinin orta düzeyde olduğu görülmüştür. Alınan tiyatro eğitimlerinin yanında duygusal zekayı destekleyici uygulamaları günlük hayatlarma dahil etmeleri önerilmektedir.

Anahtar Kelimeler: Duygusal Zeka, Tiyatro Oyuncusu, Bar on Duygusal Zeka Ölçeği 


\title{
Emotional Intelligence Levels of Theater Actors and Related Factors
}

\begin{abstract}
Emotional intelligence contributes to the more sensible use of emotions and the efficient management of positive life and professional relationships. To investigate the emotional intelligence levels of theater actors. This study was carried out with 143 people who were living in the city of Aydin between September and December 2018. Sociodemographic form and Bar on Emotional Intelligence Scale prepared by the researchers were used to collect the research data. Data were analyzed using SPSS 16 program, percentage, chi-square, independent samples $t$ test and Anova tests. The mean age of the participants was $28.5 \pm 9.48,54.5 \%$ were women, $67.1 \%$ were single, $11.2 \%$ has a diagnosis of mental illness, $64.3 \%$ defines himself as an assertive, $76.2 \%$ says that they think and try to correct the cause of a problem, $76.2 \%$ stated that performing theater is a satisfying profession and $46.9 \%$ of them find their income less than their expenses. The mean score of the Bar on Emotional Intelligence Scale was $291.35 \pm 18.40$. There was a statistically significant relationship between the mean score and income level and the year of performing theater $(p<0.05)$. Emotional intelligence levels of individuals performing theater were found to be moderate. In addition to the theater trainings they received, it is recommended that they incorporate emotional intelligence supportive practices into their daily lives.
\end{abstract}

Keywords: Emotional Intelligence, Theater Actor, Bar on Emotional Intelligence Scale 


\section{Giriş}

Duygusal zeka kavramı, ilk olarak Salovey ve Mayer'in bireylerin, kendisinin ve diğer kişilerin duygularını anlayabilmesi, bunlar arasında seçim yapabilmesi ve duygularıyla başa çıkması olarak tanımlaması ile ortaya çıkmıştır (Salovey ve Mayer, 1990). Farklı bir tanıma göre duygusal zeka, bireyin kendi duygularını anlayabilmesi, diğer bireylerin duygularına karşı empati duyması ve hayatı zenginleştirecek şekilde düzene sokması olarak tanımlanmaktadır (Goleman, 2006).

Duygusal zeka kavramı, kişinin hayattaki başarısını büyük oranda belirleyen bir beceriler bütünü olarak düşünülmektedir. Başarı ile tanımlanmak istenen yalnızca kariyer, para kazanma ve statü olmayıp bireyin bunun yanı sıra diğer insanlar ile iyi ilişkiler kurabilmesi, yaşadığ 1 yaşamdan mutlu olabilmesi ve keyfine varabilmesi olarak vurgulanmaktadır (Acar, 2002).

Duygusal zeka, duyguların kontrol edilerek mantığa uygun kullanılmasın sağlayarak günlük ve profesyonel hayatta ilişkilerin verimli yönetilebilmesine katkıda bulunur. Ayrıca yapılan bir araştırmada zeka seviyeleri aynı olan ama duygusal zekaları farklı olan bireylerde, duygusal zekası yüksek kişilerin daha başarılı oldukları görülmüştür (Shapiro, 2003).

Sanat dallarından biri olan tiyatro ile uğraşanların hayal etme yeteneği zengin, deneyime açık, zeki, hassas, estetik değerleri fazla, yaratıcı, araştırmacı, ani tepki verebilen, duygusal, hırslı, gergin, ben merkezci kişilik özellikleri olduğu bilinmektedir (Tatar, Şahintürk, Saltukoğlu ve Telvi 2013).

$\mathrm{Bu}$ araştırmada tiyatro oyunculuğu yapan bireylerin duygusal zeka düzeyleri ve bununla ilişkili faktörlerin incelenmesi amaçlanmıştır.

\section{Yöntem}

$\mathrm{Bu}$ araştırma tanımlayıc tipte olup, araştırmanın evrenini Aydın il merkezinde yer alan tiyatro oyunculuğu yapan 170 birey, örneklemini ise çalışmaya katılmayı kabul eden 143 tiyatro oyuncusu oluşturmuştur. Araştırma için Aydın Adnan Menderes Üniversitesi Hemşirelik Fakültesi Klinik Olmayan Araştırmalar Etik Kurulu'ndan yazılı izin ve katılımcılardan yazılı onam alınmıştır. Araştırma verileri anket aracılığı ile Mayıs-Temmuz 2019 tarihleri arasında kişilerin kendi bildirimlerine dayalı olarak toplanmıştır. Araştırma verilerinin toplanmasında literatür taranarak araştırmacılar tarafından ha- 
zırlanan 'Sosyodemografik Özellikler Formu' ve Dr Reuven Bar-on (1997) tarafından geliştirilmiş ve Türk toplumuna uyarlaması Mumcuoğlu (2002) tarafından yapılmış olan ‘Bar-on Duygusal Zeka Testi' kullanılmıştır.

Sosyodemografik Özellikler Formu: Kişilik özelliklerini tanımlayıc1, tiyatro eğitimleri ve süreçleri, meslek tanımları, gelir seviyelerini belirleyici 13 sorudan oluşmaktadır.

Bar-on Duygusal Zeka Testi: Bar-on Duygusal Zeka Testinin orjinali Dr Reuven Bar-on tarafından 1997'de geliştirilmiştir (Bar on, 1997). Türk toplumuna uyarlanması Mumcuoğlu (2002) tarafından yapılmıştır. Bu ölçeğin özgün hali, kişisel farkındalık, kişisel arası ilişkiler şartlara ve çevreye uyum, stres yönetimi ve genel ruh hali olmak üzere, beş alt boyuttan ve toplam 88 ifadeden oluşmaktadır. Ölçekten alınan puan ortalamasının artması duygusal zeka düzeyinin arttığını göstermektedir. Bu çalışmada Cronbach alpha değeri 0.78 olarak bulunmuştur.

Araştırma verileri SPSS 21 paket programı kullanılarak bilgisayar ile değerlendirilmiştir. Veri toplama formlarından elde edilen veriler için aritmetik ortalama, standart sapma, minimum, maksimum degerler hesapland. Nominal veriler frekans ve yüzde olarak değerlendirilmiştir. Değişkenler arası farklılığı bulmak için normal dağılım saptanması durumunda bağımsız gruplarda t-testi ve tek yönlü varyans analizi (ANOVA) testi kullanıldı. Farklılığın hangi gruptan kaynaklandığını bulmak için Tukey HSD testi uygulandı. Değişkenler arası fark ve ilişki $p<0,05$ olması durumunda anlamlı kabul edilmiştir. Normal dağılım göstermeyen verilerde değişkenlerdeki gruplara göre, bagımsız gruplarda Mann-Whitney U, Kruskal-Wallis testleri kullanılmıstır. İstatistiksel anlamlılık olarak p $<0.05$ değeri önemli kabul edilmiştir. Araştırma verilerinin Aydın il merkezinde tiyatro oyunculuğu yapan bireylerden toplanmış olması bu çalışmanın sınırlılığıdır.

\section{Bulgular}

Araştırmaya katılan oyuncuların yaş ortalaması 28.5 \pm 9.4 (min:18, max:60), \%54.5'i kadın, \%27.3'ü evli, \%72.7' si bekar, \%25.2'sinin çocuğu var, \%70'i ön lisans ve lisans eğitimine sahip, \%38.5'inin aylık gelir düzeyi 1000 TL ve altı, \%60.8'i 0-5 yıl arası tiyatro oyunculuğu yapmaktadır (Tablo 1). 
Tablo 1. Tiyatro Oyuncularının Sosyodemografik Özellikleri

\begin{tabular}{|c|c|c|}
\hline Yaş Ortalaması: & N (143) & $\%$ \\
\hline \multicolumn{3}{|l|}{$28.5 \pm 9.4(\min : 18, \max : 60)$} \\
\hline \multicolumn{3}{|l|}{ Cinsiyet } \\
\hline Kadın & 78 & 54.5 \\
\hline Erkek & 65 & 45.5 \\
\hline \multicolumn{3}{|l|}{ Medeni Durum } \\
\hline Evli & 39 & 27.3 \\
\hline Bekar & 104 & 72.7 \\
\hline \multicolumn{3}{|l|}{ Çocuk Sahibi Olma } \\
\hline Evet & 36 & 25.2 \\
\hline Hayır & 107 & 74.8 \\
\hline \multicolumn{3}{|l|}{ Eğitim Durumu } \\
\hline İlköğretim ve Lise & 33 & 23.1 \\
\hline Önlisans ve Lisans & 101 & 70 \\
\hline Lisans Üstü & 9 & 6.3 \\
\hline \multicolumn{3}{|l|}{ Aylık Gelir Düzeyi } \\
\hline 1000 TL ve altı & 55 & 38.5 \\
\hline $1001-2000 \mathrm{TL}$ & 34 & 23.8 \\
\hline 2000 TL üzeri & 54 & 37.7 \\
\hline \multicolumn{3}{|l|}{ Tiyatro oyunculuğu yapma yılı } \\
\hline $0-5$ y1l & 87 & 60.8 \\
\hline 6-11 yil & 35 & 24.5 \\
\hline 11 yıl üzeri & 21 & 14.7 \\
\hline \multicolumn{3}{|l|}{ Kişilik Özelliği } \\
\hline Girişken & 92 & 64.3 \\
\hline İçe kapanık & 33 & 23.1 \\
\hline Sinirli & 12 & 8.4 \\
\hline Karamsar & 6 & 4.2 \\
\hline \multicolumn{3}{|l|}{ Bir problem karșısında sergilenen tutum } \\
\hline Problemin sebebini düşünür çözüm üretirim & 109 & 76.2 \\
\hline Problemden uzaklaşır, çözüm bulamam & 21 & 14.7 \\
\hline Problem hakkında sadece konuşurum & 13 & 9.1 \\
\hline \multicolumn{3}{|l|}{ Ruhsal Hastalık Durumu } \\
\hline Evet & 16 & 11.2 \\
\hline Hayır & 127 & 88.8 \\
\hline
\end{tabular}

Araştırmaya katılanların Bar-on Duygusal Zeka Testi puan ortalaması 291.32+18.4 (min:220, max:353) olarak saptanmıştır (Tablo 2). Bar-on Duygusal Zeka Testi puan ortalaması ile tiyatro oyunculuğu yapma yılı arasında istatistiksel olarak anlamlı bir farklılık olduğu belirlenmiştir. Buna göre 6-11 yıldır tiyatro oyunculuğu yapanların Bar-on Duygusal Zeka Testi puan ortalaması 0-5 yıldır ve 11 yıl üzeri bir süredir tiyatro oyunculuğu yapan- 
lardan anlamlı düzeyde daha yüksek olduğu saptanmıştır $(\mathrm{P}<0.05)$ (Tablo 2).

Tablo 2. Tiyatro Oyuncularının Sosyodemografik Özelliklerine Göre Bar-on Duygusal Zeka Testi Puan Ortalamalarının Karşılaştırılması

\begin{tabular}{|c|c|}
\hline Özellikler & Bar-on Duygusal Zeka Testi Puan Ort. \\
\hline \multicolumn{2}{|l|}{ Tiyatro Oyunculuğu Yapma Yılı } \\
\hline $0-5$ yıl & $291.93 \pm 17.33$ \\
\hline $6-11$ yıl & $294.97 \pm 23.32$ \\
\hline \multirow[t]{2}{*}{11 yıl üzeri } & $282.95 \pm 9.39$ \\
\hline & $\mathrm{p}=0.044$ \\
\hline \multicolumn{2}{|l|}{ Cinsiyet } \\
\hline Kadın & $292.32+19.09$ \\
\hline \multirow[t]{2}{*}{ Erkek } & $290.20 \pm 17.61$ \\
\hline & $\mathrm{p}=0.495$ \\
\hline \multicolumn{2}{|l|}{ Çocuk Sahibi Olma } \\
\hline Evet & $290.52 \pm 21.68$ \\
\hline \multirow[t]{2}{*}{ Hayır } & $291.63 \pm 17.26$ \\
\hline & $\mathrm{p}=0.756$ \\
\hline \multicolumn{2}{|l|}{ Medeni Durum } \\
\hline Evli & $290.87 \pm 19.95$ \\
\hline \multirow[t]{2}{*}{ Bekar } & $291.16 \pm 17.99$ \\
\hline & $\mathrm{p}=0.763$ \\
\hline \multicolumn{2}{|l|}{ Eğitim Durumu } \\
\hline İlköğretim ve Lise & $288.15 \pm 24.49$ \\
\hline Önlisans ve Lisans & $292.28 \pm 16.0$ \\
\hline \multirow[t]{2}{*}{ Lisans Üstü } & $292.77 \pm 20.65$ \\
\hline & $\mathrm{p}=0.533$ \\
\hline \multicolumn{2}{|l|}{ Aylık Gelir Düzeyi } \\
\hline 1000 TL ve altı & $290.42 \pm 19.88$ \\
\hline 1001-2000 TL & $299.48 \pm 18.17$ \\
\hline \multirow[t]{2}{*}{2000 TL üzeri } & $286.38 \pm 14.78$ \\
\hline & $\mathrm{p}=0.003$ \\
\hline \multicolumn{2}{|l|}{ Kişilik Özelliği } \\
\hline Girişken & $289.98 \pm 15.22$ \\
\hline İçe kapanık & $293.15 \pm 24.79$ \\
\hline Sinirli & $291.75 \pm 16.05$ \\
\hline \multirow[t]{2}{*}{ Karamsar } & $298.66 \pm 22.55$ \\
\hline & $\mathrm{p}=0.616$ \\
\hline \multicolumn{2}{|l|}{ Bir problem karşısında sergilenen tutum } \\
\hline Problemin sebebini düşünür çözüm üretirim & $289.95 \pm 18.69$ \\
\hline Problemden uzaklaşır, çözüm bulamam & $291.61 \pm 15.83$ \\
\hline \multirow[t]{2}{*}{ Problem hakkında sadece konuşurum } & $301.30 \pm 14.42$ \\
\hline & $\mathrm{p}=0.102$ \\
\hline \multicolumn{2}{|l|}{ Ruhsal Hastalık Durumu } \\
\hline Evet & $285.87 \pm 27.23$ \\
\hline \multirow[t]{2}{*}{ Hayır } & $291.90 \pm 16.69$ \\
\hline & $\mathrm{p}=0.211$ \\
\hline
\end{tabular}


Bar-on Duygusal Zeka Testi puan ortalaması ile aylık gelir düzeyi arasında anlamlı bir ilişki saptanmıştır. Aylık gelir düzeyi 1001-2000 TL arası olan oyuncuların aylık gelir düzeyi 1000 TL ve altı olanlardan ve 2000 TL üzeri olanlardan Bar-on Duygusal Zeka Testi puan ortalaması istatistiksel olarak anlamlı düzeyde daha yüksek bulunmuştur ( $\mathrm{P}<0.05)$ (Tablo 2).

Bar-on Duygusal Zeka Testi puan ortalaması ile cinsiyet, çocuk sahibi olma, medeni durum, eğitim durumu arasında istatistiksel olarak anlamlı farklılık tespit edilmemiştir ( $\mathrm{P}>0.05)$ (Tablo 2).

\section{Tartışma}

Bu çalışmada katılımcıların Bar-on Duygusal Zeka Testi puan ortalaması 291.32+18.4 olarak bulunmuştur. Bar-on Duygusal Zeka Testi puan ortalaması ile aylık gelir düzeyi anlamlı bir ilişki saptanmıştır. Aylık gelir düzeyi 1001-2000 TL olanların Bar-on Duygusal Zeka Testi puan ortalaması diğer gelir düzeyindekilere göre daha yüksektir. Literatür incelendiğinde Özdayı ve Uğurlu (2015)'nun yürütmüş olduğu araştırmada sosyoekonomik düzey ile Bar-on Duygusal Zeka Testi puan ortalaması arasında anlamlı bir ilişki bulunmuştur. Sevindik ve ark.(2012)'nın araştırma bulgularında ise bu çalışmadan farklı olarak sosyoekonomik düzeyin Bar-on Duygusal Zeka Testi puan ortalaması ile anlamlı bir ilişkisinin olmadığı bildirilmiştir. Araştırmaların farklı gruplar üzerinde yürütülmesinin bu sonuçlar üzerinde etkili olabileceği düşünülmüştür.

Araştırmamızda, Bar-on Duygusal Zeka Testi puan ortalaması ile tiyatro oyunculuğu yaptığı yıl arasında anlamlı bir ilişki olduğu saptanmıştır. Literatürde konu ile ilgili tiyatro oyuncuları ile yürütülmüş bir çalışmaya rastlanmamıştır. Fakat tiyatro oyunculuğu yapmak için alınan eğitimlerin kişisel iletişim becerilerini geliştirmesinin Bar-on Duygusal Zeka Testi puanını etkileyerek bu farkı yaratmış olabilir.

Bar-on Duygusal Zeka Testi puan ortalaması ile cinsiyet, çocuk sahibi olma, medeni durum, eğitim durumu, kişilik özelliği, bir problem karşısında sergilenen tutum ve ruhsal hastalık durumu arasında istatistiksel olarak anlamlı farklılık tespit edilmemiştir. Literatürde konu ile ilgili farklı gruplarda yapılan çalışmalar incelendiğinde; cinsiyete göre Bar-on Duygusal Zeka Testi puanına ilişkin, bizim çalışma bulgularımızdan farklı olarak bir sağlık yüksekokulu öğrencileri ile yürütülmüş araştırmada kızların erkeklere göre Bar-on Duygusal Zeka Testi puan ortalamasının anlamlı düzeyde 
daha yüksek olduğu bildirilmiştir (Sevindik, Uncu ve Dağ 2012). Araştırma sonuçlarımız ile benzer olarak beden eğitimi ve spor öğretmenliğinde okuyan öğrenciler ile yapılmış çalışmada cinsiyet ile Bar-on Duygusal Zeka Testi puanı arasında anlamlı bir ilişki bulunmamıştır (Yalız, 2013). Yönetici olarak çalışan bireyler ile yürütülmüş bir araştırmada cinsiyet ve eğitim durumunun Bar-on Duygusal Zeka Testi puanı ile arasında bir ilişki olmadığ 1 belirlenmiştir (Acar, 2001).

Kişilik özelliğinin, Bar-on Duygusal Zeka Testi puan ortalaması ile karşılaştırıldığı çalışmalar incelendiğinde kendisini içe dönük olarak tanımlayan öğrencilerin duygusal zeka puan ortalamalarının anlamlı düzeyde daha düşük olduğu görülmüştür (Sevindik ve ark. 2012; Sardoğan ve Kaygusuz, 2006). Bizim araştırma bulgularımızdan farklı olarak kişilik özelliğinin duygusal zeka testi puanını etkilediği görülmektedir.

Duygusal zeka ile ilgili yürütülmüş araştırmalar, duyguların bireylerin harekete geçme, yardımlaşma ve iletişim gibi davranışları üzerinde önemli bir fonksiyona sahip olduğu fikrini savunmaktadır (Gros ve John, 2002; Hogan ve Roberts, 2000; Shaffer ve Shaffer, 2005; Wong ve Law, 2002). Duygusal zeka, duyguların yönetimini kapsadığı için yüksek duygusal zekaya sahip kişilerin olumsuz düşüncelerin etkisinden kurtularak yaşamdaki performanslarının arttığı bilinmektedir (Wong ve Law, 2002). Bireylerin kendi kendini kontrol zorlukları, baş etme gücü, iletişim, sorun çözme ve liderlik gibi sosyal becerileri, vicdanlı olma, güvenilir olma gibi duygusal becerilerinin iş ve günlük yaşamda performanslarını etkileyebileceği düşünülmektedir.

\section{Sonuç}

$\mathrm{Bu}$ araştırmaya göre duygusal zeka düzeyi aylık gelir düzeyi ve tiyatro oyunculuğu yapma yılından etkilenmektedir. Araştırma grubunun kişisel olarak iletişim becerisini, kişilerarası ilişkilerini etkileyecek bir uğraş olan tiyatro ile ilgilenmesine rağmen duygusal zeka düzeylerinin orta düzeyde olduğu sonucuna varılmaktadır. Alınan tiyatro eğitimlerinin yanında duygusal zekayı destekleyici uygulamaları günlük hayatlarına dahil etmeleri önerilmektedir. Farklı özelliklere sahip grupların duygusal zeka düzeyi ve ilişkili faktörlerini inceleyen araştırmaların yapılması karşılaştırma imkanı sağlayacaktır. 


\title{
EXTENDED ABSTRACT
}

\section{Emotional Intelligence Levels of Theater Actors and Related Factors}

\author{
Nükhet Kirağ - Manolya Ercan \\ Aydın Adnan Menderes University- Aydın Gynecology and Pediatrics Hospital
}

The concept of emotional intelligence is considered as a set of skills that largely determines one's success in life. It is emphasized that not only career, money making and status are desired to be defined successfully, but also the individual's ability to establish good relationships with other people, to be happy and enjoy life. Emotional intelligence contributes to the more sensible use of emotions and the efficient management of positive life and professional relationships. Emotional intelligence as the determinant of the individual's success in life, primarily with individual abilities and skills associated with recognizing and recognizing his own feelings, controlling them appropriately and realizing his self motivation for his purposes in life, being able to realize his / her self, and to establish himself in their place, It is a combination of social abilities and skills associated with interacting in it. Emotional intelligence contributes to the efficient management of relationships in daily and professional life by ensuring that emotions are controlled and used according to logic. In addition, in a study, individuals with the same intelligence levels but different emotional intelligence, people with higher emotional intelligence were more successful. To investigate the emotional intelligence levels of theater actors. This research is descriptive, and the universe of the research is composed of 170 actors acting in the city of Aydın, and 143 theater actors whose sample agreed to participate in the study. Written consent was obtained from Aydın Adnan Menderes University Faculty of Nursing Non-Clinical Research Ethics Committee and written consent was obtained from the participants. The research data were collected through the questionnaire between May and July 2019 based on individuals' own reports. In collecting the research data, the 'Bar-on Emotional Intelligence Test' developed by Mumcuoğlu (2002) and 'Sociodemographic Properties Form' prepared by the researchers by scanning the literature and developed by Mumcuoğlu (2002) were used. This study was car- 
ried out with 143 people who were living in the city of Aydın between September and December 2018. Sociodemographic Characteristics Form: It consists of 13 questions that define personality characteristics, theater education and processes, job descriptions, and income levels. Bar-on Emotional Intelligence Test: The original Bar-on Emotional Intelligence Test was developed by Dr Reuven Bar-on in 1997 (Bar on, 1997). It was adapted to Turkish society by Mumcuoğlu (2002). The original form of this scale consists of five sub-dimensions and a total of 88 expressions: personal awareness, interpersonal relations, compliance with the conditions and environment, stress management and general mood. The increase in the mean score obtained from the scale shows that the level of emotional intelligence increases. In this study, Cronbach's alpha value was found to be 0.78 .

Research data were evaluated by computer using SPSS 21 package program. Arithmetic mean, standard deviation, minimum and maximum values were calculated for the data obtained from data collection forms. Nominal data were evaluated in frequency and percentage. In order to find the difference between variables, in the case of normal distribution, t-test and oneway analysis of variance (ANOVA) test were used in independent groups. Tukey HSD test was applied to find out from which group the difference originated. The difference between the variables and the relationship was considered significant if $\mathrm{p}<0.05$. According to the groups in the variables, Mann-Whitney $U$ and Kruskal-Wallis tests were used in the non-normally distributed data. As statistical significance, $p<0.05$ value was accepted as important. The fact that the research data was collected from individuals acting as theater actors in the city center of Aydın is the limitation of this study.Sociodemographic form and Bar on Emotional Intelligence Scale prepared by the researchers were used to collect the research data. Data were analyzed using SPSS 16 program, percentage, chi-square, independent samples $\mathrm{t}$ test and Anova tests. The mean age of the participants was $28.5 \pm$ $9.48,54.5 \%$ were women, $67.1 \%$ were single, $11.2 \%$ has a diagnosis of mental illness, $64.3 \%$ defines himself as an assertive, $76.2 \%$ says that they think and try to correct the cause of a problem, $76.2 \%$ stated that performing theater is a satisfying profession and $46.9 \%$ of them find their income less than their expenses. The mean score of the Bar on Emotional Intelligence Scale was $291.35 \pm 18.40$. There was a statistically significant relationship between the mean score and income level and the year of performing theater $(p<0.05)$. 
Emotional intelligence levels of individuals performing theater were found to be moderate. In addition to the theater trainings they received, it is recommended that they incorporate emotional intelligence supportive practices into their daily lives.

\section{Kaynakça / References}

Acar, F. T. (2001). Duygusal zeka yeteneklerinin göreve yönelik ve insana yönelik liderlik davranışlan ile ilişkisi: Banka şube müdürleri üzerine bir alan araştırması. Yayımlanmamış doktora tezi, İstanbul Ünv. Sosyal Bilimler Enstitüsü, İstanbul

Acar F. (2002). Duygusal zeka ve liderlik. Erciyes Üniversitesi Sosyal Bilimler Enstitüsü Dergisi, 12, 53-68.

Baron, R. (1997). The BarOn emotional quotient inventory (BarOn EQ-i). Toronto, ON: Multi-Health Systems Inc.

Goleman, D. (2006). Duygusal zeka neden IQ' dan daha önemlidir? Yuksel BS (Çeviren). 30. Baskı, İstanbul: Varlık Yayınları.

Gross, J. J. ve John, O. P. (2002). Wise emotion regulation. In L. Feldman Barrett \& P. Salovey (Eds.), The Wisdom Of Feelings: Psychological Processes In Emotional Intelligence (297-318) . New York, Guilford.

Hogan, R.T. ve Roberts, B.W. (2000). A Socioanalytic perspective on person/environment interaction. In W. B. Walsh, K. H. Craik, \& R. H. Price (Eds.), New Directions In Person-Environment Psychology (1-24) Mahway, NJ: Earlbaum.

Mumcuoğlu, Ö. (2002). Bar-On duygusal zeka testinin Türkçe dilsel eşdeğerlik, güvenirlik ve geçerlik çalışması. Yayınlanmamış Yüksek Lisans Tezi, Marmara Üniversitesi Eğitim Bilimleri Enstitüsü. İstanbul.

Özdayı, N., ve Uğurlu, F. (2015). Futbol hakemlerinin duygusal zeka ve iletişim beceri düzeyleri arasındaki ilişkinin incelenmesi. Uluslararası Spor Egzersiz ve Antrenman Bilimi Dergisi, 1(1), 31-39.

Salovey, P., ve Mayer, J. D. (1990). Emotional intelligence. Imagination, cognition and personality, 9(3), 185-211.

Sardoğan, M. E., ve Kaygusuz, C. (2006). Antisosyal kişilik bozukluğu tanısı almış ve almamış olan bireylerin duygusal zeka düzeyleri açısından incelenmesi. Ege Ĕ̆itim Dergisi, 7(1), 85-102.

Sevindik, F., Uncu, F., ve Dağ, D. G. (2012). Sağlık yüksekokulu öğrencilerinin duygusal zekâ düzeylerinin bazı değişkenler açısından incelenmesi. $F l^{-}$ rat Üniversitesi Sağlık Bilimleri Tip Dergisi, 26(1), 21-26. 
Shaffer, R. D. ve Shaffer M. A. (2005). Emotional intelligence abilities, personality and work place performance. Hong Kong Baptist University Academy of Management Best Conference Paper, HR: M 1.

Tatar, A., Sahintürk, H., Saltukoglu, G., ve Telvi, S. (2013). Tiyatro oyuncularinin beş faktör modeli çerçevesinden kisilik özelliklerinin incelenmesi ve meslek grubu profillerinin olusturulması. Türk Psikoloji Dergisi, 28(72), 1.

Yalız, D. (2013). Anadolu üniversitesi beden eğitimi ve spor öğretmenliği bölümü öğrencilerinin duygusal zeka düzeyleri. Pamukkale Journal of Sport Sciences, 4(2), 94-111.

Wong, C.S. ve Law, K.S. (2002). The effects of leader and follower emotional intelligence on performance and attitude: An exploratory study. Leadership Quarterly, 13, 243-274.

\section{Kaynakça Bilgisi / Citation Information}

Kırağ, N. ve Ercan, M. (2020). Tiyatro oyuncularının duygusal zeka düzeyleri ve ilişkili faktörler. OPUS-Uluslararası Toplum Araştırmaları Dergisi, 15(Özel Sayı), 5032-5043. DOI: 10.26466/opus.639984 